Check for updates

Cite this: RSC Adv., 2017, 7, 55012

Received 23rd September 2017 Accepted 27th November 2017

DOI: 10.1039/c7ra10538j

rsc.li/rsc-advances

\section{Enhanced xenon adsorption and separation with an anionic indium-organic framework by ion exchange with $\mathrm{Co}^{2+} \uparrow$}

\author{
Bo-yu Liu, You-jin Gong, Xiao-nan Wu, Qiang Liu, Wei Li, Shun-shun Xiong, (DD * \\ Sheng $\mathrm{Hu}^{*}$ and Xiao-lin Wang
}

The separation of xenon/krypton is industrially significant and an environmental concern. Adsorptive capture and separation xenon from krypton using porous MOFs provides an energy and capital efficient approach compared with the current cryogenic distillation process. Herein, we investigated the adsorptive $\mathrm{Xe} / \mathrm{Kr}$ separation potential of three anion In-MOFs (CPM-5, CPM- 6 and the $\mathrm{CO}^{2+}$-exchanged framework analogue $\left.\mathrm{CO}^{2+}-\mathrm{CPM}-6\right)$. Anionic In-MOF $\mathrm{CO}^{2+}-\mathrm{CPM}-6$ with $\mathrm{Co}^{2+}$ ions in pore spaces has been obtained using a simple cation-exchange process and exhibits much higher Xe adsorption capacity and $\mathrm{Xe} / \mathrm{Kr}$ selectivity than organic cation-analogues CPM-5 $\left(\left[\left(\mathrm{CH}_{3}\right)_{2} \mathrm{NH}_{2}\right]^{+}\right)$and $\mathrm{CPM}-6\left(\left[\mathrm{CH}_{3} \mathrm{NH}_{3}\right]^{+}\right)$, verified by single-component gas isotherms, IAST calculations and breakthrough experiments. The enhanced adsorptive $\mathrm{Xe} / \mathrm{Kr}$ separation performance for $\mathrm{CO}^{2+} \mathrm{CPM}-6$ could be due to the increased pore size or accessible micropore volume and enhanced electric field within the pore spaces, which could induce strong interaction with $\mathrm{Xe}$ and simultaneously reduce the affinity with $\mathrm{Kr}$.

\section{Introduction}

Rare or noble gases xenon (Xe) and krypton (Kr) are commonly encountered in low concentrations (Xe exists in the atmosphere at 0.087 ppmv, and krypton (Kr) at $1.14 \mathrm{ppmv}$ ) and their extraction is consequently difficult. ${ }^{1}$ However, these noble gases are industrially valuable and have many significant uses including commercial lighting, medical imaging, insulation and lasers., ${ }^{1,2}$ On the other hand, radioisotopes of xenon and krypton $\left({ }^{85} \mathrm{Kr}\right.$ and $\left.{ }^{133} \mathrm{Xe}\right)$ are released as by-products from nuclear reprocessing plants. For environmental concerns and recycling of noble gases, the long-lived and hazardous ${ }^{85} \mathrm{Kr}$ (half life of 10.8 years) should be separated and captured from effluent gas mixtures of nuclear fuel reprocessing plants., Meanwhile, separation and capture of xenon from radioactive krypton in the off-gas stream after a short-time decay of the short half-life xenon isotope would provide a new resource of xenon for industrial use. Currently, a 20/80 molar mixture of $\mathrm{Xe}-\mathrm{Kr}$ obtained as a by-product in cryogenic air separation must undergo further cryogenic distillation to produce pure xenon and krypton. And cryogenic process is also suggested for the removal of radioactive noble gases from off-gas streams in future nuclear reprocessing plants. However, this process is

Institute of Nuclear Physics and Chemistry, China Academy of Engineering Physics, Mianyang, Sichuan, 621900, P. R. China.E-mail: husheng205@caep.cn; ssxiong@ caep.cn

† Electronic supplementary information (ESI) available. See DOI: $10.1039 / \mathrm{c} 7 \mathrm{ra} 10538 \mathrm{j}$ highly energy and capital intensive. ${ }^{5}$ Therefore, effective capture and separation of $\mathrm{Xe}-\mathrm{Kr}$ at room temperature becomes an urgent and significant issue to be resolved.

Adsorptive separation of $\mathrm{Xe}-\mathrm{Kr}$ using porous materials at room temperature could be a suitable alternative to cryogenic process for its easy operation and low costs. Thus, adsorbents with high $\mathrm{Xe} / \mathrm{Kr}$ selectivity and capacity are essential for the design of adsorptive separation process such as pressure swing adsorption (PSA) and vacuum swing adsorption (VSA). ${ }^{6}$ In this regard, zeolites and active carbon have been used and evaluated for $\mathrm{Xe} / \mathrm{Kr}$ separation at ambient conditions. ${ }^{7-9}$ However, their low Xe capacity and selectivity limits their practical use. Metalorganic frameworks (MOFs), a new kind of hybrid crystalline porous material which are hybrid lattices of organic ligands and metal nodes (metal ions or clusters), have attracted enormous attention over the past two decades for its ultrahigh specific surface area, tunable pore structure, adjustable chemical environment and high thermal stability. ${ }^{\mathbf{1 0 - 1 2}}$ Owing to this feature, MOFs appear to be promising as cost-effective and efficient adsorbents for gas storage and separation. ${ }^{13-21}$ Recently, the effective separation of noble gases Xe and Kr using MOFs has received much more attention and become a new area of focus. ${ }^{22-36}$

Up to date, studies on $\mathrm{Xe} / \mathrm{Kr}$ separation using MOFs are still scarce. ${ }^{37}$ Wang et al. showed that $\mathrm{Co}_{3}(\mathrm{HCOO})_{6}$ can commensurately adsorb Xe and high $\mathrm{Xe} / \mathrm{Kr}$ selectivity due to the unique pore size and channel shape. ${ }^{38}$ Thallapally et al. reported that NiDOBDC adsorbs more Xe compared to activated carbon and also showed that silver loading within NiDOBDC notably 
enhances both Xe capacity and $\mathrm{Xe} / \mathrm{Kr}$ selectivity. ${ }^{39,40}$ Cooper et al. reported that a porous organic cage CC3, though not a MOF, shows significantly high Xe capacity and $\mathrm{Xe} / \mathrm{Kr}$ selectivity at low concentrations. ${ }^{\mathbf{4 1}}$ Xiong et al. reported a flexible zinc tetrazolate framework $\left[\mathrm{Zn}(\mathrm{mtz})_{2}\right]$ which exhibits breathing behaviour on Xe adsorption and has a high $\mathrm{Xe} / \mathrm{Kr}$ selectivity measured by breakthrough experiment using binary $\mathrm{Xe}-\mathrm{Kr}$ gas mixture. ${ }^{42}$ Recently, Thallapally et al. reported that SBMOF-1 exhibits by far the highest reported xenon adsorption capacity and a remarkable $\mathrm{Xe} / \mathrm{Kr}$ selectivity under conditions pertinent to nuclear fuel reprocessing. ${ }^{43}$ Computational screening studies carried by Snurr et al. suggest that MOFs with cylindrical pores just large enough to fit a single xenon atom would have the highest $\mathrm{Xe} / \mathrm{Kr}$ selectivity but better materials remains to be discovered. ${ }^{44}$

Recent studies have indicated several features that are desirable for enhancing adsorption capacity and selectivity of xenon at room temperature. One feature is the suitable pore size commensurate with the size of Xe molecule (4.1 $\mathrm{A}$ ). Another factor currently receiving considerable attention is introducing individual localized binding sites using methods such as (1) deposition of Ag clusters in the porous MOFs and (2) creation of unsaturated metal sites (also called open-metal sites) and more polarizing organic groups $(-\mathrm{I},-\mathrm{OH}) \cdot{ }^{\mathbf{4 0 , 4 5 - 4 7}}$ Furthermore, the porous solid-Xe molecule interactions can also be enhanced by employing the electric field across the pore space that is capable of polarizing Xe molecules and increasing the interaction with charged internal pore surface or charged extraframework species. ${ }^{40}$ However, this approach is rarely studied because most of MOFs exhibit an electrically neutral framework. Thus, it is essential and meaningful to investigate the Xe adsorption and separation properties of anionic MOFs and the influence of cations on their separation performance. Indium(III) often exhibits an eight-coordinated central building block with four equivalent carboxylate ligands and has been frequently used to design and synthesis of anionic MOFs with low connectivity and high surface areas. Two anionic In-MOF: $\left[\left(\mathrm{CH}_{3}\right)_{2} \mathrm{NH}_{2}\right]\left[\mathrm{In}_{3^{-}}\right.$ $\left.\mathrm{O}(\mathrm{BTC})_{2}\left(\mathrm{H}_{2} \mathrm{O}\right)_{3}\right]_{2}\left[\mathrm{In}_{3}(\mathrm{BTC})_{4}\right] \cdot$ solvent (denoted as CPM-5, CPM = crystalline porous materials) and $\left[\mathrm{CH}_{3} \mathrm{NH}_{3}\right]\left[\mathrm{In}_{3} \mathrm{O}(\mathrm{BTC})_{2}\left(\mathrm{H}_{2}-\right.\right.$ $\left.\mathrm{O})_{3}\right]_{2}\left[\operatorname{In}_{3}(\mathrm{BTC})_{4}\right]$. solvent (CPM-6, BTC $=1,3,5$-benzenetricarboxylate) firstly reported by Zheng et al. exhibit high surface areas, good hydrothermal stability, coupled with suitable pore size (4-6 $⿱$ ) and strong charge-induced forces within the internal pore space which render them good candidates for the study of Xe selective sorption properties.

In this work, we firstly describe facile separation of Xe from $\mathrm{Kr}$ at room temperature using three anionic microporous MOFs based upon In(III) ions, CPM-5, CPM-6 and the $\mathrm{Co}^{2+}$-exchanged framework analogue $\mathrm{Co}^{2+}$-CPM-6. More smaller and higher polar $\mathrm{Co}^{2+}$ ions could be easily introduced into the pores of the anionic microporous framework using a simple ion-exchange with organic cations $\left(\left[\mathrm{CH}_{3} \mathrm{NH}_{3}\right]^{+}\right)$, which provides an approach to tune the pore volume and electric field across the pore space. Experimental adsorption isotherms and breakthrough curves under packed-bed mixture flow conditions indicates that $\mathrm{Co}^{2+}$ CPM-6 exhibits much higher Xe adsorption capacity and $\mathrm{Xe} / \mathrm{Kr}$ selectivity compared with its organic cation-analogues CPM-5 $\left(\left[\left(\mathrm{CH}_{3}\right)_{2} \mathrm{NH}_{2}\right]^{+}\right)$and CPM-6 $\left(\left[\mathrm{CH}_{3} \mathrm{NH}_{3}\right]^{+}\right)$.

\section{Experimental}

\section{Materials and measurements}

All reagents and solvents were used as received from commercial suppliers without further purification. Thermogravimetric analyses (TGA) were performed on a TA TGA/Q500 analyzer with heating rate of $5{ }^{\circ} \mathrm{C} \min ^{-1}$ from 27 to $800{ }^{\circ} \mathrm{C}$. Powder X-ray diffraction (PXRD) patterns were recorded by a Bruker D8advance Powder X-ray Diffractometer Instrument operated at $40 \mathrm{kV}$ and $44 \mathrm{~mA}$ with a scan of $1.0 \mathrm{deg} \mathrm{min}^{-1}$. Analyses for the concentrations of $\mathrm{Co}^{2+}, \mathrm{In}^{3+}$ were carried out on an Inductively Coupled Plasma-Optical Emission Spectroscopy (ICP-OES) analyzer. Calibration curves for ICP-OES were prepared by dilution of commercially available standards with the sample dissolves in concentrated $\mathrm{HCl}$, and diluted to proper concentration for measurement. The verification of $\mathrm{Co}^{2+}$ in CPM- 6 was also carried out on a Perkin-Elmer PHI-5702 multi-functional Xray photoelectron spectroscopy (XPS) with $\mathrm{Al} \mathrm{K} \alpha$ radiation.

\section{Preparation of CPM-5 and CPM-6}

CPM-5 was synthesized as a slight modification of the procedure of ref. 49, in which a mixture of $0.2 \mathrm{~g} \operatorname{In}\left(\mathrm{NO}_{3}\right)_{3} \cdot 5 \mathrm{H}_{2} \mathrm{O}$ and $0.17 \mathrm{~g} \mathrm{H}_{3} \mathrm{BTC}$ was stirred in a mixed solution of $\mathrm{H}_{2} \mathrm{O} / \mathrm{DMF}(1.0 \mathrm{~g} /$ $4.0 \mathrm{~g}$ ) for 1 hour, and then transferred to the Teflon-lined stainless steel autoclave $(20 \mathrm{ml})$, and kept at $120{ }^{\circ} \mathrm{C}$ for 5 days. CPM-6 was synthesized using the same procedure in which the DMF was replaced by NMF. After washed by methanol several times, the colorless crystals were obtained.

\section{Preparation of $\mathrm{Co}^{2+}$-CPM-6}

The as-prepared CPM-6 sample was ion-exchanged with $\mathrm{Co}^{2+}$, immersed in methanol containing $0.1 \mathrm{M} \mathrm{Co}\left(\mathrm{NO}_{3}\right)_{2}$ and changed with fresh new $\mathrm{Co}\left(\mathrm{NO}_{3}\right)_{2}$ methanol solution every day for four days. And then the samples were filtered and washed with methanol several times to obtain $\mathrm{Co}^{2+}$ ions exchanged CPM-6 designated as $\mathrm{Co}^{2+}-\mathrm{CPM}-6$.

\section{Gas adsorption measurements}

$\mathrm{Xe}, \mathrm{Kr}, \mathrm{Ar}, \mathrm{N}_{2}$ adsorption and desorption isotherms were measured on the Micromeritics 3Flex Surface Characterization Analyzer. To get the solvent free framework, the fresh samples of CPM-5 and CPM- 6 were guest-exchanged with dry methanol 4 times per day for 2 days, filtered and degassed at ambient temperature for $6 \mathrm{~h}$, and then vacuumed at $180{ }^{\circ} \mathrm{C}$ overnight to measurements. The fresh samples of $\mathrm{Co}^{2+}$-CPM- 6 were filtered and washed by methanol several times and degassed at ambient temperature for $6 \mathrm{~h}$, and then vacuumed at $180^{\circ} \mathrm{C}$ overnight to measurements. The adsorption isotherms at $77 \mathrm{~K}$ were measured upon the liquid nitrogen bath. The temperatures of adsorption isotherms at $273 \mathrm{~K}$ and $298 \mathrm{~K}$ were maintained using a Micromeritics's ISO Controller (Sub-Ambient, Thermoelectric Cooled Dewar). Ultrahigh-purity-grade (>99.999\%) Xe, Kr, Ar, $\mathrm{N}_{2}$ and $\mathrm{He}$ gases were applied in the adsorption measurements. 


\section{Results and discussion}

\section{Characterization of CPM-5, CPM-6 and $\mathrm{Co}^{2+}-\mathrm{CPM}-6$}

CPM-5 and CPM-6 were synthesized using a slight modification of a published procedure. ${ }^{49}$ The phase purity of the sample was confirmed by PXRD. CPM- 5 and CPM- 6 firstly reported by Zheng et al. have the same framework structure just with different organic cations $\left(\left(\mathrm{CH}_{3}\right)_{2} \mathrm{NH}_{2}{ }^{+}\right.$for CPM-5, $\mathrm{CH}_{3} \mathrm{NH}_{3}{ }^{+}$for CPM-6). As shown in Fig. 1, CPM-5 and CPM- 6 have a fascinating cagewithin-cage architecture structure. The bigger $\operatorname{In}_{24}$ sodalite cage built with negatively charged single-metal building blocks $\left\{\mathrm{In}\left(\mathrm{CO}_{2}\right)_{4}\right\}$ and $\mathrm{BTC}^{3-}$ ligands with $25.7 \times 25.7 \times 25.7 \AA^{3}$ in dimension is far too large for capture of Xe atoms. The small inner $\mathrm{In}_{12}$ cage comprised of four positively charged trimeric clusters $\left\{\mathrm{In}_{3} \mathrm{O}\right\}$ and three $\mathrm{BTC}^{3-}$ ligands with a dimension of 8.7 $\mathrm{A}$. The $\mathrm{In}_{12}$ cage was interconnected with the $\mathrm{In}_{24}$ cage by 12 BTCs ligands which segment the pore space of the large sodalite cage into multiple domains. Drifting cations - $\left(\mathrm{CH}_{3}\right)_{2} \mathrm{NH}_{2}{ }^{+}$ (CPM-5) and $\mathrm{CH}_{3} \mathrm{NH}_{3}{ }^{+}$(CPM-6) are amid these networks. The whole pore space partitioned by BTC linkers and occupied by cations exhibits microporous pore network structure. The micropore size of 4-6 ^ was calculated using Horvath-Kawazoe method. Additionally, removal of the three dangling water on $\left\{\mathrm{In}_{3}(\mathrm{O})\left(\mathrm{O}_{2} \mathrm{CR}\right)_{6}\left(\mathrm{H}_{2} \mathrm{O}\right)_{3}\right\}$ of the inner $\mathrm{In}_{12}$ cage during the activation procedure generates $\mathrm{In}^{3+}$ sites being exposed to pore surface for Xe adsorption. ${ }^{48}$ Interestingly, the outer $\operatorname{In}_{24}$ cage composed of $\left\{\operatorname{In}\left(\mathrm{CO}_{2}\right)_{4}\right\}$ units is negatively charged while the inner $\operatorname{In}_{12}$ cage made from $\left\{\operatorname{In}_{3}(\mathrm{O})\left(\mathrm{O}_{2} \mathrm{CR}\right)_{6}\left(\mathrm{H}_{2} \mathrm{O}\right)_{3}\right\}$ units is positively charged, resulting in an electric field within the pore space. ${ }^{49}$ What's more, the organic cations within the pores could be easily exchanged by metal ions to tune the pore size and electric field for Xe adsorption. ${ }^{50}$ In this work, we choose $\mathrm{Co}^{2+}$ ions to exchange with $\left[\mathrm{CH}_{3} \mathrm{NH}_{3}\right]^{+}$using the as-synthesized CPM6 samples based on several reasons: (1) bivalent $\mathrm{Co}^{2+}$ ions having higher polarizing ability compared to $\left[\mathrm{CH}_{3} \mathrm{NH}_{3}\right]^{+}$and bivalent metal ion would enhance electric field within the pore

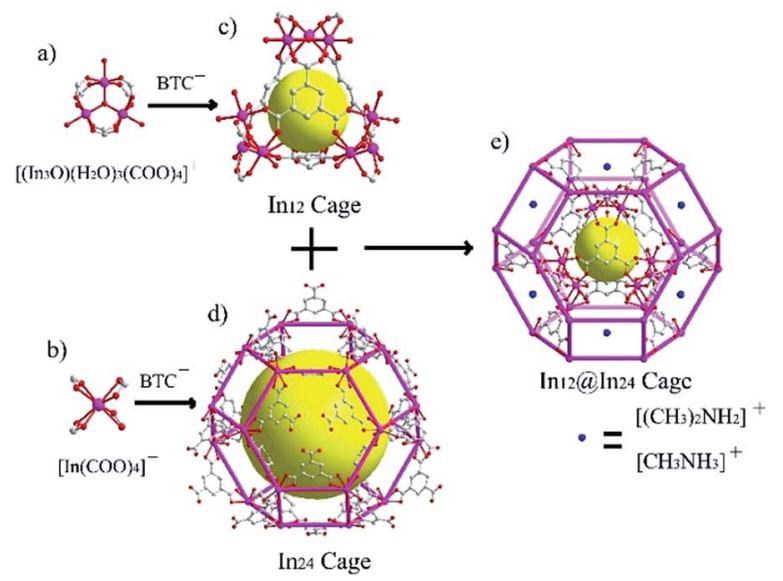

Fig. 1 (a-e) Structures of trimeric $\left\{\left(\ln _{3} \mathrm{O}\right)\left(\mathrm{H}_{2} \mathrm{O}\right)_{3}\right\}$ unit, monomeric $\mathrm{In}^{3+}$ ion, $\ln _{12}$ cage, $\ln _{24}$ cage and $\ln _{12}\left(\ln _{24}\right.$ cage, respectively. The purple solid lines represent BTCs. The blue solid balls represent the cations $\left(\left[\left(\mathrm{CH}_{3}\right)_{2} \mathrm{NH}_{2}\right]^{+},\left[\mathrm{CH}_{3} \mathrm{NH}_{3}\right]^{+}\right.$). The small yellow ball represents the $\operatorname{In}_{12}$ cage cavity. The big yellow ball represents $\ln _{24}$ cage cavity. space, (2) for M-MOF-74 (M $=\mathrm{Co}^{2+}, \mathrm{Mg}^{2+}, \mathrm{Zn}^{2+}$ and $\left.\mathrm{Ni}^{2+}\right), \mathrm{Co}^{2+}$ shows significantly stronger binding to Xe molecules than $\mathrm{Mg}^{2+}$, $\mathrm{Zn}^{2+}$ and $\mathrm{Ni}^{2+}$, which has been proved by experimental and simulated results, ${ }^{45,51,52}$ (3) $\mathrm{Co}^{2+}$ is smaller than $\left[\mathrm{CH}_{3} \mathrm{NH}_{3}\right]^{+}$, consequently releasing more space volume for Xe adsorption.
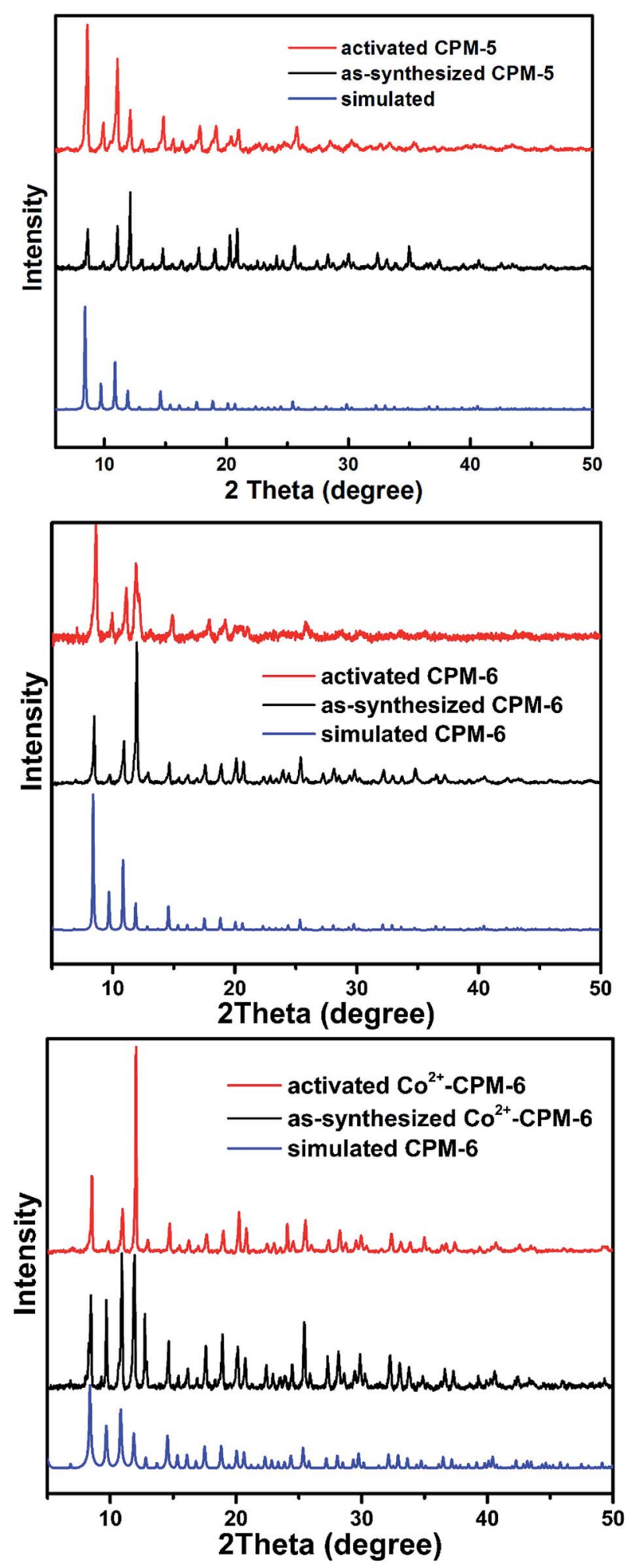

Fig. 2 The PXRD patterns of CPM-5, CPM-6, and $\mathrm{CO}^{2+}-\mathrm{CPM}-6$. 
$\mathrm{Co}^{2+}$-exchange sample, $\mathrm{Co}^{2+}$-CPM- 6 was obtained by soaking assynthesized CPM-6 samples into a methanol solution of $\mathrm{Co}\left(\mathrm{NO}_{3}\right)_{2} \cdot \mathrm{In}^{3+} / \mathrm{Co}^{2+}$ molar ratio in $\mathrm{Co}^{2+}-\mathrm{CPM}-6$ measured by ICP-OES is 29 , which means $62 \%\left[\mathrm{CH}_{3} \mathrm{NH}_{3}\right]^{+}$cations has been replaced by $\mathrm{Co}^{2+}$ ions. And XPS result of $\mathrm{Co}^{2+}-\mathrm{CPM}-6$ (see Fig. S13†) also showed that $\mathrm{Co}^{2+}$ ions were successfully introduced into the framework.

Powder X-ray diffraction patterns indicate that pure phase samples of CPM-5 and CPM-6 have been successfully synthesized (shown in Fig. 2). $\mathrm{Co}^{2+}$-CPM-6 nearly has the same PXRD patterns with CPM-6, which shows that $\mathrm{Co}^{2+}-\mathrm{CPM}-6$ maintains its framework structure and crystalline state well during the $\mathrm{Co}^{2+}$-exchange process. And the PXRD patterns for the activated samples illustrate that CPM-5, CPM-6 and $\mathrm{Co}^{2+}-\mathrm{CPM}-6$ are stable enough for gas sorption measurements after their activation procedure.

As shown in Fig. 3, $\mathrm{N}_{2}$ sorption isotherms of CPM-5, CPM-6 and $\mathrm{Co}^{2+}$-CPM- 6 at $77 \mathrm{~K}$ indicate that all three samples exhibit a typical reversible type-I behavior. We adopted two models: Langmuir and BET surface area to precisely evaluate the specific surface areas of these three materials. The Langmuir and BET surface areas of CPM-5 are $768 \mathrm{~m}^{2} \mathrm{~g}^{-1}$ and $521 \mathrm{~m}^{2} \mathrm{~g}^{-1}$, respectively. And the micropore volume of CPM-5 (using $t$-plot method) was also calculated to be $0.242 \mathrm{~cm}^{3} \mathrm{~g}^{-1}$. The (Langmuir) BET surface areas and micropore volume of CPM-6 were calculated to be $\left(871 \mathrm{~m}^{2} \mathrm{~g}^{-1}\right) 583 \mathrm{~m}^{2} \mathrm{~g}^{-1}$ and $0.282 \mathrm{~cm}^{3} \mathrm{~g}^{-1}$, which are higher than that of CPM-5. This could be due to small cation size of $\left[\mathrm{CH}_{3} \mathrm{NH}_{3}\right]^{+}$in CPM-6 taking up less pore space compared with $\left[\left(\mathrm{CH}_{3}\right)_{2} \mathrm{NH}_{2}\right]^{+}$in CPM-5. The surface area and micropore volume of CPM-5 and CPM- 6 in this work are consistent with the reported literature. ${ }^{49} \mathrm{Co}^{2+}$-CPM- 6 with the small $\mathrm{Co}^{2+}$ ions for charge-compensating exhibits the highest (Langmuir) BET surface areas and micropore volume compared with CPM-5 and CPM-6 and were calculated to be (1055) $671 \mathrm{~m}^{2} \mathrm{~g}^{-1}$ and $0.305 \mathrm{~cm}^{3} \mathrm{~g}^{-1}$, respectively. Langmuir model has a relative higher value than BET model. The differences between Langmuir and BET surface areas could be attributed to

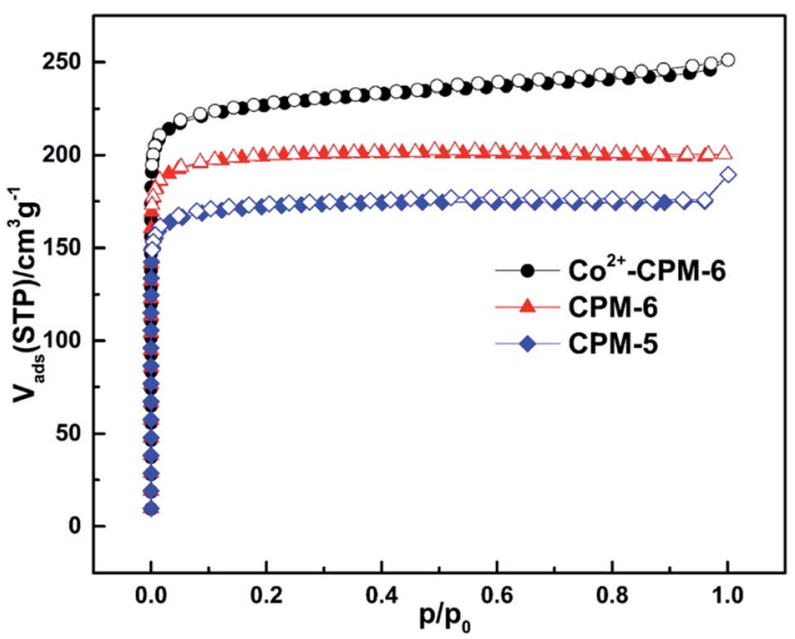

Fig. $3 \mathrm{~N}_{2}$ sorption isotherms of CPM-5, CPM- 6 and $\mathrm{CO}^{2+}-\mathrm{CPM}-6$ at $77 \mathrm{~K}$. the different hypothesis that Langmuir model assumes monolayer adsorption while BET model assumes multilayer adsorption. Thus it is a reasonable result that Langmuir model has a higher value than BET model. However, the specific surface areas of these two models don't differ too much, which manifests that CPM-5, CPM-6 and $\mathrm{Co}^{2+}$-CPM-6 belong to the micropore materials and the pore sizes won't exceed $7 \AA$ (see Fig. S3 $\dagger$ ). The DFT pore sizes distribution calculated by DFT model shows
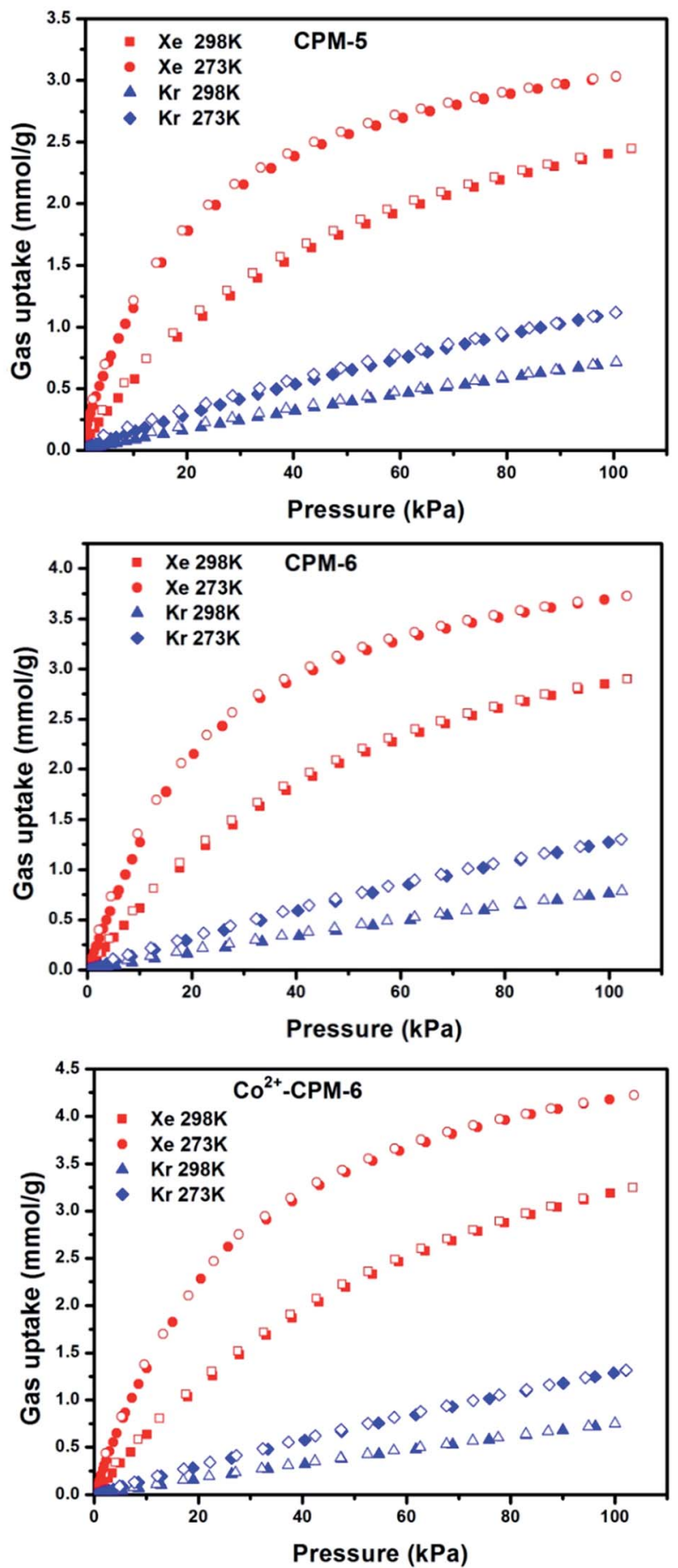

Fig. $4 \mathrm{Xe}$ and $\mathrm{Kr}$ adsorption and desorption isotherms of CPM-5, CPM- 6 and $\mathrm{CO}^{2+}-\mathrm{CPM}-6$ at $273 \mathrm{~K}$ and $298 \mathrm{~K}$. 


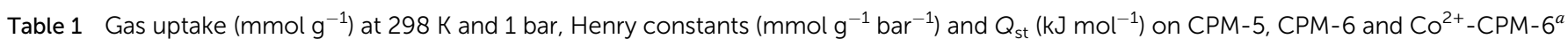

\begin{tabular}{|c|c|c|c|c|c|c|c|c|}
\hline & $N_{\text {Xe }}\left(\mathrm{mmol} \mathrm{g}^{-1}\right)$ & $N_{\mathrm{Kr}}\left(\mathrm{mmol} \mathrm{g}^{-1}\right)$ & $N_{\mathrm{Xe}} / N_{\mathrm{Kr}}$ & $H_{\text {Xe }}\left(\mathrm{mmol} \mathrm{g}^{-1} \mathrm{bar}^{-1}\right)$ & $H_{\mathrm{Kr}}\left(\mathrm{mmol} \mathrm{g}{ }^{-1} \mathrm{bar}^{-1}\right)$ & $H_{\mathrm{Xe}} / H_{\mathrm{Kr}}$ & $Q_{\text {st }}(\mathrm{Xe})$ & $Q_{\mathrm{st}}(\mathrm{Kr})$ \\
\hline CPM-5 & 2.44 & 0.71 & 3.1 & 6.06 & 0.89 & 6.8 & 25.0 & 17.3 \\
\hline CPM-6 & 2.89 & 0.78 & 3.7 & 6.15 & 0.85 & 7.2 & 25.1 & 17.1 \\
\hline
\end{tabular}

${ }^{a} N_{\mathrm{Xe}}$ and $N_{\mathrm{Kr}}$ represent Xe and Kr uptake, respectively; $H_{\mathrm{Xe}}$ and $H_{\mathrm{Kr}}$ represent Henry's constant of Xe and $\mathrm{Kr}$.

that $\mathrm{Co}^{2+}-\mathrm{CPM}-6$ exhibits a little decrease of pore space in the range of 5.4-6.4 $\AA$ and a distinct increase of pore space in the range of 6.4-8.6 $\AA$ compared with CPM-6. These results show that ion-exchange with small metal ions in anionic framework could provide an effective way to enhance the specific surface area and adjust the micropore volume or pore size (see Fig. S3†).

\section{Single component sorption isotherms, Henry's constants and isosteric heats of adsorption}

The establishment of the permanent porosity enabled us to examine their gas sorptions of Xe and Kr. As shown in Fig. 4. Pure adsorption and desorption isotherms for $\mathrm{Xe}$ and $\mathrm{Kr}$ in CPM-5, CPM-6 and $\mathrm{Co}^{2+}$-CPM-6 were measured at $298 \mathrm{~K}$ and $273 \mathrm{~K}$ up to 1 bar. Adsorption and desorption isotherms for Xe and $\mathrm{Kr}$ are fully reversible and the sorption of Xe exhibits type-I behavior, which was typical for strong adsorbates sorption in microporous materials. The uptake of Xe at $298 \mathrm{~K}$ and 1 bar for CPM-5 and CPM-6 are $2.44 \mathrm{mmol} \mathrm{g}^{-1}$ and $2.89 \mathrm{mmol} \mathrm{g}^{-1}$, 3.4 times and 3.7 times higher than their $\mathrm{Kr}$ uptakes (0.71 mmol g $\mathrm{m}^{-1}$ for CPM-5 and $0.78 \mathrm{mmol} \mathrm{g}^{-1}$ for CPM-6). The Xe uptake of $\mathrm{Co}^{2+}$-CPM-6 at $298 \mathrm{~K}$ and 1 bar is $3.20 \mathrm{mmol} \mathrm{g}^{-1}$, which is 4.3 times higher than its $\mathrm{Kr}$ uptake $\left(0.75 \mathrm{mmol} \mathrm{g}^{-1}\right)$. It should be noted that $\mathrm{Co}^{2+}$-CPM- 6 has an obvious higher Xe uptake than CPM-6 but a slightly low Kr uptake compared with CPM-6. The enhancement of Xe adsorption capacity for $\mathrm{Co}^{2+}$ CPM-6 could be due to an increase in the accessible micropore volume. The slightly lower $\mathrm{Kr}$ uptake of $\mathrm{Co}^{2+}-\mathrm{CPM}-6$ may be due to the decrease of micropore volumes in the range of 5.4-6.4 $\AA$, that are suitable for $\mathrm{Kr}$ adsorption.

In order to understand and explain the different performances for these three MOFs on uptake of Xe over $\mathrm{Kr}$, we calculated the Henry's constants based on single component sorption isotherms to evaluate the gas-adsorbent interactions. Henry's constant is a useful measure of adsorbents' affinity for adsorbates, since it represents the partition of the adsorbate between its bulk phase and adsorbed phase at very low pressures. $^{38}$ The Henry's constants for Xe and Kr in CPM-5, CPM-6 and $\mathrm{Co}^{2+}$-CPM- 6 were calculated using low-pressure isotherms at $298 \mathrm{~K}$. We fitted the low-pressure isotherms which passed through the original point and appeared linear fit, and obtained slopes of these fitting lines which represent the Henry's constants (see Fig. S6-S11†). As shown in Table 1, the order of the calculated Henry's constants for Xe is $\mathrm{Co}^{2+}-\mathrm{CPM}-6>\mathrm{CPM}-6>$ CPM-5. Interestingly, the order of the calculated Henry's constant for $\mathrm{Kr}$ is CPM-5 > CPM- $6>\mathrm{Co}^{2+}-\mathrm{CPM}-6$, which is opposite to the order of the Henry's constants for Xe. The enhancement of Henry's constant for Xe in $\mathrm{Co}^{2+}-\mathrm{CPM}-6$ could be due to the more polarized electric field across the pore space or strong interaction between $\mathrm{Co}^{2+}$ ions and Xe molecules. The lower Henry's constant for $\mathrm{Kr}$ in $\mathrm{Co}^{2+}-\mathrm{CPM}-6$ is main due to the decreased pore volumes in the range of 5.4-6.4 $\AA$ that are just fit for adsorption of $\mathrm{Kr}$ atoms. To verify adsorption strength of Xe and $\mathrm{Kr}$ in CPM-5, CPM-6 and $\mathrm{Co}^{2+}-\mathrm{CPM}-6$, we calculated the isosteric heats of adsorption $\left(Q_{\text {st }}\right)$ from single component adsorption isotherms as a function of quantity adsorbed at different temperatures ( $273 \mathrm{~K}$ and $298 \mathrm{~K}$ ) using the ClausiusClapeyron equation. As shown in Fig. 5, Xe $Q_{\text {st }}$ values of CPM-5 and CPM-6 at low loadings are $25.0 \mathrm{~kJ} \mathrm{~mol}^{-1}$ and $25.1 \mathrm{~kJ} \mathrm{~mol}^{-1}$, which are nearly the same. $\mathrm{Co}^{2+}$-CPM-6 has a higher Xe $Q_{\mathrm{st}}$ value (25.9 $\mathrm{kJ} \mathrm{mol}^{-1}$ ) than CPM-5 and CPM-6. The $\mathrm{Kr} Q_{\text {st }}$ values of these three MOFs at low loading are as follows: CPM-5 $\left(17.3 \mathrm{~kJ} \mathrm{~mol}^{-1}\right)>$ CPM-6 (17.1 $\left.\mathrm{kJ} \mathrm{mol}^{-1}\right)>\mathrm{Co}^{2+}$-CPM-6 $\left(16.6 \mathrm{~kJ} \mathrm{~mol}^{-1}\right)$, which matches well with the order of the Henry's constants for Kr. All these results indicates that introduce of small and polar $\mathrm{Co}^{2+}$ ions could enhance the Xe interaction with pore surface and reduce affinity of $\mathrm{Kr}$. The $\mathrm{Xe} / \mathrm{Kr}$ selectivity calculated by the radio of Henry's constants follows the order: $\mathrm{Co}^{2+}$-CPM-6 (7.8) > CPM-6 (7.2) > CPM-5 (6.8), which indicates that $\mathrm{Co}^{2+}-\mathrm{CPM}-6$ has the strongest interaction with Xe molecules of these three MOFs.

\section{IAST selectivity}

Ideal adsorbed solution theory (IAST) is a thermodynamic method which can predict the selectivity of gas mixtures based

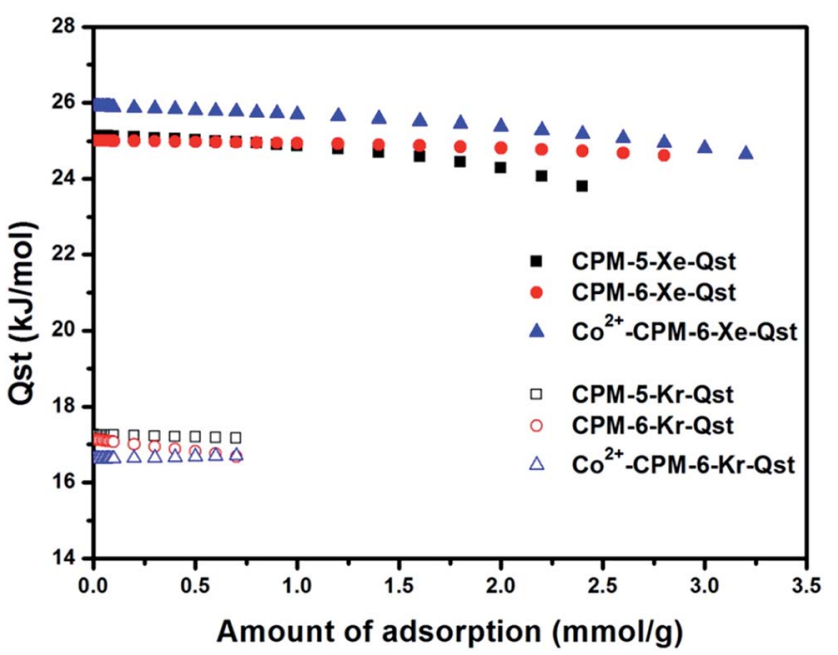

Fig. 5 The isosteric heats of adsorption $\left(Q_{\mathrm{st}}\right)$ for $\mathrm{Xe}$ and $\mathrm{Kr}$ in CPM-5, CPM- 6 and $\mathrm{CO}^{2+}-\mathrm{CPM}-6$. 
on the experimental single component adsorption isotherms and has been proved to be an effective approach to evaluate the separation ability of various materials. ${ }^{53-55}$ In order to obtain good prediction by IAST, pure isotherms of Xe and Kr were fitted using the dual-site Langmuir-Freundlich (DSLF) model (see Table $\mathrm{S} 1 \dagger){ }^{56}$ In this work, we predicted the $\mathrm{Xe} / \mathrm{Kr}$ selectivity by IAST for $20 / 80 \mathrm{Xe} / \mathrm{Kr}$ gas mixture, which is an industrially relevant composition for $\mathrm{Xe}-\mathrm{Kr}$ gas mixture to assess the potential of CPM-5, CPM- 6 and $\mathrm{Co}^{2+}$-CPM- 6 on Xe/Kr separation. As shown in Fig. 6, $\mathrm{Co}^{2+}$-CPM-6 exhibits a distinct enhancement on $\mathrm{Xe} / \mathrm{Kr}$ selectivity compared with CPM- 6 after the $\mathrm{Co}^{2+}$-exchange process. The IAST $\mathrm{Xe} / \mathrm{Kr}$ selectivities of these three materials follow the order of $\mathrm{Co}^{2+}$-CPM-6 (9.3) > CPM-6 (7.3) > CPM-5 (7.1) at $100 \mathrm{kPa}$ and $298 \mathrm{~K}$, which agrees with the results from Henry's constants. This could be attributed to the stronger electric field across the pore space with $\mathrm{Co}^{2+}$ ions as compensating cations in $\mathrm{Co}^{2+}$-CPM-6, that is capable of polarizing Xe atoms and increasing its interaction with charged pore surface or $\mathrm{Co}^{2+}$ ions. The IAST Xe/Kr selectivity of $\mathrm{Co}^{2+}$-CPM- 6 is among the reported high $\mathrm{Xe} / \mathrm{Kr}$ selectivity porous materials: SBMOF-1 (16), SBMOF-2 (10), $\mathrm{Co}_{3}(\mathrm{HCOO})_{6}$ (11), CC3 (12.5), Ag@MOF74Ni (11.5), Co-MOF-74 (12). ${ }^{43,46}$

\section{Dynamic breakthrough experiments}

We also carried out the breakthrough experiments at room temperature to evaluate the potential of these three MOFs for the adsorptive separation of $\mathrm{Xe} / \mathrm{Kr}$ mixtures, under the real world conditions (see Fig. S12 $\dagger$ ). Fig. 7 shows the breakthrough curves of Xe and $\mathrm{Kr}$ upon separation of a 20/80 Xe/Kr mixture on the column packed with CPM-5, CPM-6 and $\mathrm{Co}^{2+}{ }^{2+} \mathrm{CPM}-6$ at $298 \mathrm{~K}$ and 1 bar. For all three MOFs, Kr firstly elutes from the column, and was detected at $\sim 9 \mathrm{~min}^{-1}$ after the gas mixture was introduced into the column. While Xe retains strongly in the column and was detected at a breakthrough time of $\sim 15 \mathrm{~min}^{-1}$ for CPM-5, $24 \mathrm{~min}^{-1}$ for CPM-6 and $35 \mathrm{~min}^{-1}$ for $\mathrm{Co}^{2+}-\mathrm{CPM}-6$, respectively. The $\mathrm{Kr}$ concentration at the column outlet exceeding the feed concentration indicates

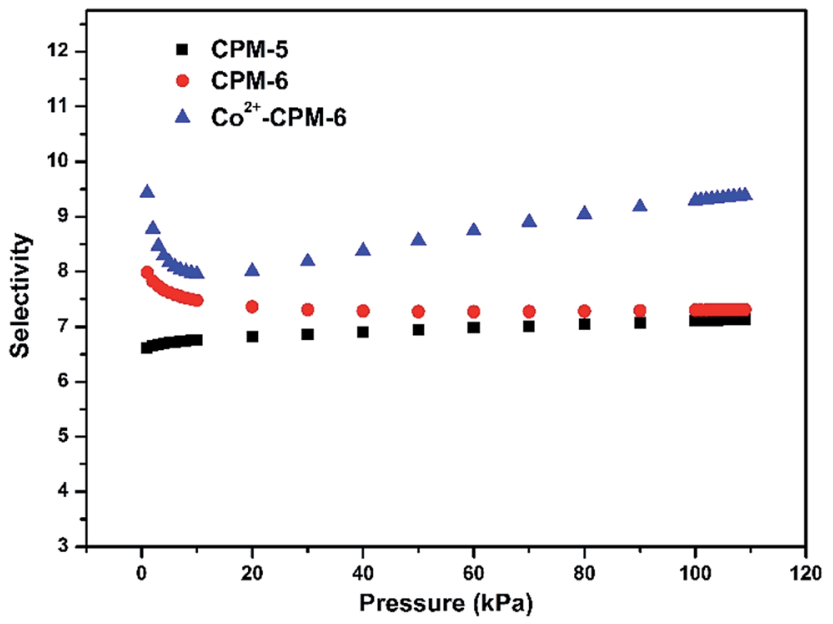

Fig. 6 IAST-predicted Xe/Kr selectivities of CPM-5, CPM- 6 and $\mathrm{CO}^{2+}$ CPM- 6 for 20/80 Xe/Kr gas mixture at $298 \mathrm{~K}$.

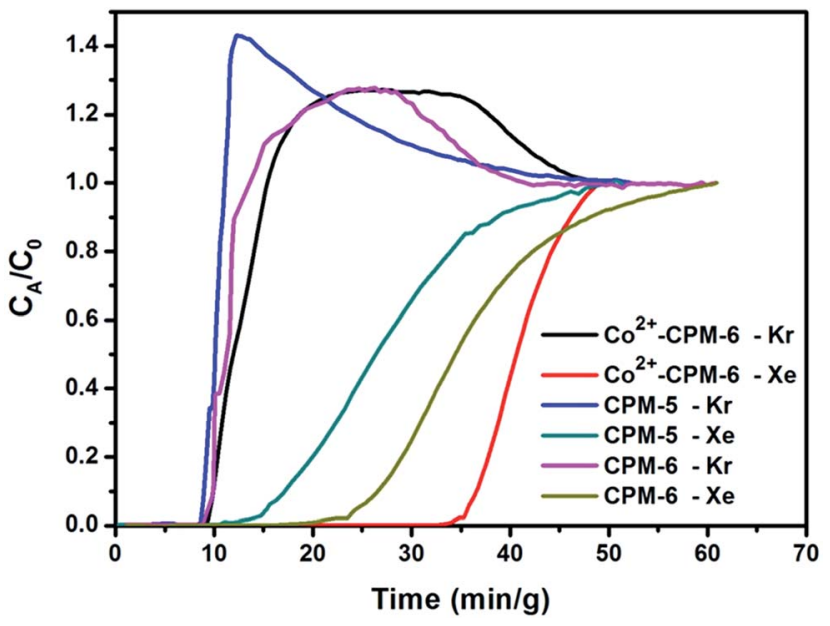

Fig. 7 The breakthrough curves of CPM-5, CPM- 6 and $\mathrm{CO}^{2+}-\mathrm{CPM}-6$ for a $20: 80 \mathrm{Xe} / \mathrm{Kr}$ gas mixture at $298 \mathrm{~K}$ and 1 bar. The flow rate of $\mathrm{He}$

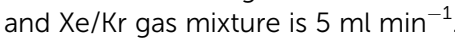

a significantly stronger interaction for Xe molecules than $\mathrm{Kr}$ molecules with the adsorbents during the breakthrough process. The Xe/Kr selectivity of CPM-5, CPM- 6 and $\mathrm{Co}^{2+}$-CPM-6 was calculated to be 6.2, 6.6 and 8.9 respectively, based on the adsorption capacity of the two gases, agreeable with the IAST selectivity derived from the single gas adsorption isotherms. These results indicate that after $\mathrm{Co}^{2+}$-exchange process, $\mathrm{Co}^{2+}$ CPM-6 has a remarkable higher Xe/Kr selectivity than CPM-5 and CPM-6 not only at equilibrium, but also under kinetic flow conditions. What's more, $\mathrm{Co}^{2+}$-CPM- 6 exhibits less diffusion effect for Xe than CPM-5 and CPM-6 in the breakthrough process and would provide better $\mathrm{Xe} / \mathrm{Kr}$ separation performance in the practical application. This could be due to the improvement of pore size and micropore volumes in the framework during the $\mathrm{Co}^{2+}$-exchange process. The high Xe capacity and Xe/ $\mathrm{Kr}$ selectivity suggests $\mathrm{Co}^{2+}-\mathrm{CPM}-6$ a promising candidate for $\mathrm{Xe} / \mathrm{Kr}$ adsorptive separation.

\section{Conclusions}

In this work, we have investigated adsorptive $\mathrm{Xe} / \mathrm{Kr}$ separation potential of three anionic porous indium-organic frameworks (CPM-5, CPM-6 and the $\mathrm{Co}^{2+}$-exchanged framework analogue $\mathrm{Co}^{2+}$-CPM-6). A new anionic In-MOF Co ${ }^{2+}-\mathrm{CPM}-6$ with $\mathrm{Co}^{2+}$ ions in pore spaces has been obtained using a simple cationexchange process and exhibits much higher Xe adsorption capacity and Xe/Kr selectivity than CPM-5 and CPM-6, verified by the single-component gas isotherms, IAST calculations and breakthrough experiments. Small and polarized $\mathrm{Co}^{2+}$ ions could increase the pore size or accessible micropore volumes and enhance the electric field within pore space, which could induce strong interaction with $\mathrm{Xe}$ and simultaneously reduce the affinity with $\mathrm{Kr}$, suggesting the potential of $\mathrm{Co}^{2+}-\mathrm{CPM}-6$ to be a promising candidate material for $\mathrm{Xe} / \mathrm{Kr}$ adsorptive separation. The introduction of small and polarized metal ions such as $\mathrm{Co}^{2+}$ ions into an anionic MOF to tune its pore size or pore volume 
and electric field across pore space may be a promising strategy to enhance Xe adsorption capacity and $\mathrm{Xe} / \mathrm{Kr}$ separation performance of MOFs.

\section{Conflicts of interest}

Authors declare no conflicts of interest and have reached an agreement of the final version of manuscript.

\section{Acknowledgements}

This work was supported by "Radiochemistry 909 program" in China Academy of Engineering Physics (CAEP), the National Natural Science Foundation of China (Grants 21501158).

\section{Notes and references}

1 F. G. Kerry, Industrial Gas Handbook: Gas Separation and Purification, CRC Press, Boca Raton, Florida, 2007.

2 S. C. Cullen and E. G. Gross, Science, 1951, 113, 580-582.

3 A. Turkevich, L. Winsberg, H. Flotow and R. M. Adams, Proc. Natl. Acad. Sci. U. S. A., 1997, 94, 7807-7810.

4 N. R. Soelberg, T. G. Garn, M. R. Greenhalgh, J. D. Law, R. Jubin, D. M. Strachan and P. K. Thallapally, Sci. Technol. Nucl. Install., 2013, 72496.

5 J. Izumi, Waste Gas Treatment using Zeolites in NuclearRelated Industries, in Handbook of Zeolites Science and Technology, Marcel Dekker, Inc., New York, 2003.

6 R. T. Yang, Adsorbents: Fundamentals and Applications, John Wiley \& Sons. Inc., Hoboken, 2003.

7 C. G. Saxton, A. Kruth, M. Castro, P. A. Wright and R. F. Howe, Microporous Mesoporous Mater., 2010, 129, 68-73.

8 R. E. Bazan, M. Bastos-Neto, A. Moeller, F. Dreisbach and R. Staudt, Adsorption, 2011, 17, 371-383.

9 X. Feng, Z. Zong, S. K. Elsaidi, J. B. Jasinski, R. Krishna, P. K. Thallapally and M. A. Carreon, J. Am. Chem. Soc., 2016, 138, 9791-9794.

10 G. Férey, Chem. Soc. Rev., 2008, 37, 191-214.

11 S. Kitagawa, R. Kitaura and S. Noro, Angew. Chem., Int. Ed., 2004, 43, 2334-2375.

12 O. M. Yaghi, M. O'Keeffe, N. W. Ockwig, H. K. Chae, M. Eddaoudi and J. Kim, Nature, 2003, 423, 705-714.

13 D. M. D'Alessandro, B. Smit and J. R. Long, Angew. Chem., Int. Ed., 2010, 49, 6058-6082.

14 R. Matsuda, R. Kitaura, S. Kitagawa, Y. Kubota, R. V. Belosludov, T. C. Kobayashi, H. Sakamoto, T. Chiba, M. Tkata, Y. Kawazoe and Y. Mita, Nature, 2005, 436, 238241.

15 Z. Zhang, Z. Z. Yao, S. Xiang and B. Chen, Energy Environ. Sci., 2014, 7, 2868-2899.

16 S. Xiang, Y. He, Z. Zhang, H. Wu, W. Zhou, R. Krishna and B. Chen, Nat. Commun., 2012, 3, 954-960.

17 J. R. Li, R. J. Kuppler and H. C. Zhou, Chem. Soc. Rev., 2009, 38, 1477-1504.

18 P. Nugent, Y. Belmabkhout, S. D. Burd, A. J. Cairns, R. Luebke, K. Forrest, T. Pham, S. Ma, B. Space, L. Wojtas, M. Eddaoudi and M. J. Zaworotko, Nature, 2013, 495, 80-84.
19 S. S. Xiong, Y. J. Gong, H. X. Wang, H. L. Wang, Q. Liu, M. Cu, X. L. Wang, B. L. Chen and Z. Y. Wang, Chem. Commun., 2014, 50, 12101-12104.

20 R. E. Morris and P. S. Wheatley, Angew. Chem., Int. Ed., 2008, 47, 4966-4981.

21 J. R. Li, Y. G. Ma, M. C. McCarthy, J. Sculley, J. M. Yu, H. K. Jeong, P. B. Balbuena and H. C. Zhou, Coord. Chem. Rev., 2011, 255, 1791-1823.

22 M. V. Parkes, C. L. Staiger, J. J. Perry IV, M. D. Allendorf and J. A. Greathouse, Phys. Chem. Chem. Phys., 2013, 15, 9093-9106.

23 T. Van Heest, S. L. Teich-McGoldrick, J. A. Greathouse, M. D. Allendorf and D. S. Sholl, J. Phys. Chem. C, 2012, 116, 13183-13195.

24 Y. S. Bae, B. G. Hauser, Y. J. Colon, J. T. Hupp, O. K. Farha and R. Q. Snurr, Microporous Mesoporous Mater., 2013, 169, 176-179.

25 K. V. Lawler, Z. Hulvey and P. M. Forster, Chem. Commun., 2013, 49, 10959-10961.

26 C. A. Fernandez, J. Liu, P. K. Thallapally and D. M. Strachan, J. Am. Chem. Soc., 2012, 134, 9046-9049.

27 C. M. Simon, R. Mercado, S. K. Schnell, B. Smit and M. Haranczyk, Chem. Mater., 2015, 27, 4459-4475.

28 S. J. Lee, T. U. Yoon, A. R. Kim, S. Y. Kim, K. H. Cho, Y. K. Hwang, J. W. Yeon and Y. S. Bae, J. Hazard. Mater., 2016, 320, 513-520.

29 J. Liu, P. K. Thallapally and D. Strachan, Langmuir, 2012, 28, 11584-11589.

30 M. H. Mohamed, S. K. Elsaidi, T. Pham, K. A. Forrest, H. T. Schaef, A. Hogan, L. Wojtas, W. Xu, B. Space, M. J. Zaworotko and P. K. Thallapally, Angew. Chem., Int. Ed., 2016, 55, 8285-8289.

31 Q. Wang, S. S. Xiong, Z. H. Xiang, S. M. Peng and D. P. Cao, Sci. China: Chem., 2016, 59, 643-650.

32 Q. Wang, H. Wang, S. M. Peng, X. Peng and D. P. Cao, J. Phys. Chem. C, 2014, 118, 10221-10229.

33 S. K. Elsaidi, M. H. Mohamed, C. M. Simon, E. Braun, T. Pham, K. A. Forrest, W. Xu, D. Banerjeer, B. Space, M. J. Zaworotko and P. K. Thallapally, Chem. Sci., 2017, 8, 2373-2380.

34 R. S. Patil, D. Banerjee, C. M. Simon, J. L. Atwood and P. K. Thallapally, Chem.-Eur. J., 2016, 22, 12618-12623.

35 S. K. Ghose, Y. Li, A. Yakovenko, A. Yakovenko, E. Dooryhee, L. Ehm, L. E. Ecker, A. Dippel, G. J. Halder, D. M. Strachan and P. K. Thallapally, J. Phys. Chem. Lett., 2015, 6, 1790-1794.

36 J. Liu, C. A. Fernandez, P. F. Martin, P. K. Thallapally and D. M. Strachan, Ind. Eng. Chem. Res., 2014, 53, 12893-12899. 37 D. Banerjee, A. J. Cairns, J. Liu, R. K. Motkuri, S. K. Nune, C. A. Fernandez, R. Krishna, D. M. Strachan and P. K. Thallapally, Acc. Chem. Res., 2015, 48, 211-219.

38 H. Wang, K. Yao, Z. Zhang, J. Jagiello, Q. Gong, Y. Han and J. Li, Chem. Sci., 2014, 5, 620-624.

39 P. K. Thallapally, J. W. Grate and R. K. Motkuri, Chem. Commun., 2012, 48, 347-349.

40 J. Liu, D. M. Strachan and P. K. Thallapally, Chem. Commun., 2014, 50, 466-468.

41 L. Chen, P. S. Reiss, S. Y. Chong, D. Holden, K. E. Jelfs, T. Hasell, M. A. Little, A. Kewley, M. E. Briggs, 
A. Stephenson, K. M. Thomas, J. A. Armstrong, J. Bell, J. Busto, R. Boel, J. Liu, D. M. Strachan, P. K. Thallapally and A. I. Cooper, Nat. Mater., 2014, 134, 18892-18895.

42 S. S. Xiong, Q. Liu, Q. Wang, W. Li, Y. Tang, X. L. Wang, S. Hu and B. L. Chen, J. Mater. Chem. A, 2015, 3, 10747-10752.

43 D. Banerjee, C. M. Simon, A. M. Plonka, R. K. Motkuri, J. Liu, X. Chen, B. Smit, J. B. Parise, M. Haranczyk and P. K. Thallapally, Nat. Commun., 2016, 7, 11831.

44 B. J. Sikora, C. E. Wilmer, M. L. Greenfield and R. Q. Snurr, Chem. Sci., 2012, 3, 2217-2223.

45 J. J. Perry, S. L. Teich-McGoldrick, S. T. Meek, J. A. Greathouse, M. Haranczyk and M. D. Allendorf, J. Phys. Chem. C, 2014, 118, 11685-11698.

46 X. Chen, A. M. Plonka, D. Banerjee, R. Krishna, H. T. Schaef, S. Ghose, P. K. Thallapally and J. B. Parise, J. Am. Chem. Soc., 2015, 137, 7007-7010.

47 S. T. Meek, S. L. Teich-McGoldrick, J. J. Perry, J. A. Greathouse and M. D. Allendorf, J. Phys. Chem. C, 2012, 116, 19765-19772.
48 S. K. Ghose, Y. Li, A. Yakovenko, E. Dooryhee, L. Ehm, L. Ecker, A.-C. Dippel, G. J. Halder, D. M. Strachan and P. K. Thallapally, J. Phys. Chem. Lett., 2015, 6, 1790-1794.

49 S.-T. Zheng, J. T. Bu, Y. F. Li, T. Wu, F. Zuo, P. Y. Feng and X. H. Bu, J. Am. Chem. Soc., 2010, 132, 17062-17064.

50 F. Nouar, J. Eckert, J. F. Eubank, P. Forster and M. Eddaoudi, J. Am. Chem. Soc., 2009, 131, 2864-2870.

51 T. Vazhappilly, T. K. Ghanty and B. N. Jagatap, J. Phys. Chem. C, 2016, 120, 10968-10974.

52 S. J. Lee, K. C. Kim, T. U. Yoon, M. B. Kim and Y. S. Bae, Microporous Mesoporous Mater., 2016, 236, 284-291.

53 A. L. Myers and J. M. Prausnitz, AIChE J., 1965, 11, 121-127. 54 R. Babarao, Z. Q. Hu, J. W. Jiang, S. Chempath and S. I. Sandler, Langmuir, 2007, 23, 659-666.

55 S. R. Challa, D. S. Sholl and J. K. Johnson, J. Chem. Phys., 2002, 116, 814-824.

56 L. Czepirski and J. Jagiello, Chem. Eng. Sci., 1989, 44, 797801. 